\title{
Recycling of Electronic Waste, Using Basic and Acid Leaching
}

\author{
Miguel Aguilar Cortes', Martha Lilia Domínguez Patiño \\ ${ }^{1}$ Graduate Engineering and Applied Science, Universidad Autónoma del Estado de Morelos, Cuernavaca, \\ México \\ ${ }^{2}$ Faculty of Chemical and Engineering Sciences, Universidad Autónoma del Estado de Morelos, Cuernavaca, \\ México \\ Email: maguilarc@uaem.mx
}

Received 31 January 2016; accepted 27 March 2016; published 30 March 2016

Copyright (C) 2016 by authors and Scientific Research Publishing Inc.

This work is licensed under the Creative Commons Attribution International License (CC BY).

http://creativecommons.org/licenses/by/4.0/

(c) (i) Open Access

\section{Abstract}

This recycling of printed circuit board (TCI) for the production of metals, given the environmental degradation that can cause toxic substances of these, is the reuse of valuable materials recovered from the TCI, this being an economic engine that promotes the recycling of this waste. This paper presents a methodology for evaluating the reaction kinetics and leaching of metals that form the metal substrate, which have environmental and energy advantages, so the generation of new recovery techniques metals from the TCI low environmental and energy impact is increasingly necessary, for it is essential to establish the parameters affecting the reaction rate and identify design alternatives to determine whether or not sustainable, economically viable and that does not pollute. The method adopted was a leaching acid samples, where the full factorial method employed two experimental levels to evaluate the influence of: leaching time, temperature of the aqueous leach solution, reaction kinetics and solid/liquid, on the percentage of metal extraction. Subsequently, the metals are obtained by calcining and smelting the resulting salts by addition of acid liquor.

\section{Keywords}

TCI, Acidic and Basic Leaching and Electronic Waste

\section{Introduction}

In the recovery of waste metal from the printed circuit boards (TCI), the purpose is to achieve the treatment with minimal risk to the environment and human health, existing recycling processes are currently not very friendly 
with the ecosystem and health, today these must be sustainable and efficient, in addition to complying with the agreements of the Basel Convention, especially the responsibility extended producer (REP), proclaimed in the United Nations Conference on environment and development, held in 1992 in Brazil, being established in principle 16 of the Rio Declaration [1].

The REP sets in principle 16 "national authorities should endeavor to promote the internalization of environmental costs and the use of economic instruments, taking into account the criteria that which contaminates must, in principle, bear the costs of pollution, with due regard to the public interest and without distorting trade and international investment" [2]. One of the advantages to introducing this concept, is eliminating mismanagement in the market, Since currently the costs of products not considered the cost to finance its management at the time of become waste, but with the addition of these in the analysis of the product life cycle, companies met with the principle of extended producer responsibility.

The project was initiated in January of 2012, as subject of the doctoral thesis in materials of the center of research in engineering and applied sciences at the Autonomous University of the State of Morelos (UAEM). This is intended to determine a methodology for recycling of waste electrical and electronic equipment (WEEE) in the context of economic, social and environmental feasibility. Electronic waste is largely scrapping metal mixed with other materials. Significant amounts of iron, aluminum, copper and some precious metals such as gold and silver can be found among the metals. Plastics and glass also appear in appreciable amounts.

According to the OECD definition, it is considered as electronic waste. "Entire apparatus which uses a supply of electrical energy and that has reached the end of its useful life" [3]. E-waste directive adopted by the European Union distinguishes ten categories of waste: large appliances; small appliances; computer equipment and telecommunications; electrical consumption; lighting apparatus; tools electrical and electronic; toys or equipment sport and free time; (with the exception of all implanted or infected products) medical devices; instruments of surveillance and control; [4] vending machines.

The study focuses on electronic waste from equipment's given floor of the Faculty of Chemical Sciences and Engineering (FCQeI) of the Autonomous University of the State of Morelos (UAEM), it correspond to category 3 (computer equipment and telecommunications) the European directive, specifically computers.

Electronic waste is the waste that has most increased in the developed world; according to data of the European of the Environment Agency, the volume of e-waste is increasing three times faster than the urban waste; in short, the volume of electronic waste is growing between 16 and $28 \%$ every five years, caused by the reduction in the cost of computing, mobile phones and other electronics equipment, coupled with the obsolescence of technology.

Fortunately in Mexico there is no e-waste coming from other countries, as it happens in Asia or Africa. But an increase in the number of cell phones and computers that are thrown away, just in the UAEM, discarded approximately 10 tons a year of waste has been generated. The problem largely is because there are no strategies for the recycling of these devices.

As an example, in the case of computers, the reuse (reuse) is a phenomenon of great importance, so much so that more than half of the teams receive such treatment. Therefore, the overhaul plays an essential role in the recycling of WEEE.

\section{Overall Objective}

$>$ Or evaluate analytical methods of recovery and refining of metals from e-waste.

\section{Particular Objectives}

$>$ Or assess the recovery of precious metals by the method of aqua regia.

$>$ Or assess the recovery of precious metals by the encuarte method.

\section{Scope of the Investigation}

Removal and separation of electronic components will be done manually with a soldering iron, separating its electronics and parts metal, processor of pin which is one of the parts with the highest content of metals of interest, involves a first cut of manual material, Blade, later becomes a reduction in size with a (mechanical) mill pulverizing the TCI. 
These stages are carried out in the laboratories of the Faculty of chemical sciences and engineering and the Center for research and applied science of the UAEM.

\section{Methodology}

Recover metals contained in electronic waste specifically printed circuit board of computer. To retrieve these computer ICT, a leaching process, was used on a system with aqua regia, by the following procedure (Figure 1):

Computer printed circuit was properly characterized using scanning electron microscopy of electrons (SEM) in the laboratory of the Centre of research in engineering and applied sciences (CIICAp) of the UAEM by SEM-EDS. We used a scanning electron microscope brand LEO $1450 \mathrm{VP}$; with a 10 - 2 to 10 - 5 amp probe current and voltage of 2 to $30 \mathrm{kv}$ for a scope of 300,000 amplifications (see Figure 2). The team is equipped with a solid state detector, which allows performing semi-quantitative microanalysis by dispersion of energies (EDS) [5].

SEM images showed gold and lead in electronic component pin processor. It was observed an array not defined with two phases. The metal fraction by weight for the Au is $0.07 \%$ (Figure 3). Also gold and nickel in nickel and integrated electronic component surface and potentially Platinum on the RAM card; metal fractions of nickel by weight were 1.36 and 50.26 respectively; the metal fraction to the integrated surface gold was 28.54\% (Figure 3).

The SEM images to the pins of the serial and parallel ports presented metal species titanium, copper, and gold. There were three phases fully identified with homogeneous surface and textured ductile in the case of copper. Stands out the metal fraction of gold by weight by 20 percent and $43.30 \%$ in the case of nickel (Figure 4).

The leaching experiments were carried out at atmospheric pressure in a reactor of glass (ball flask). The reactor is mounted on a plate of warming and magnetic stirring and temperature controller. The agitator is steel coated with teflon (Figure 5).

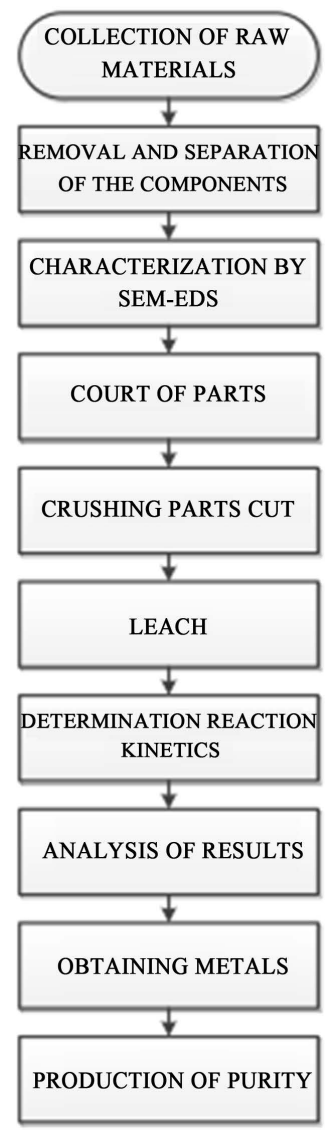

Figure 1. Methodology for the recovery of metals laboratory. 


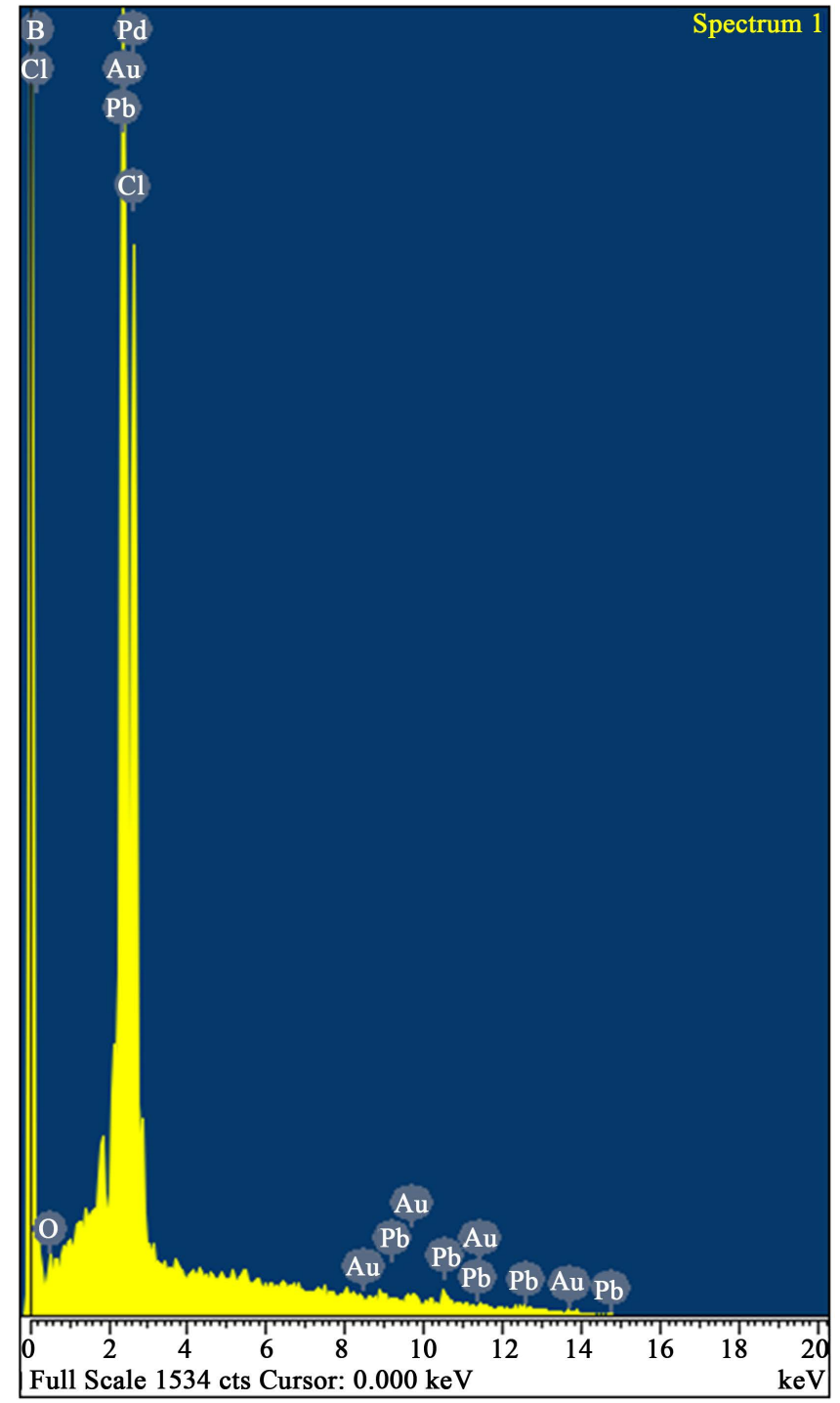

Figure 2. Scanning electron microscope.

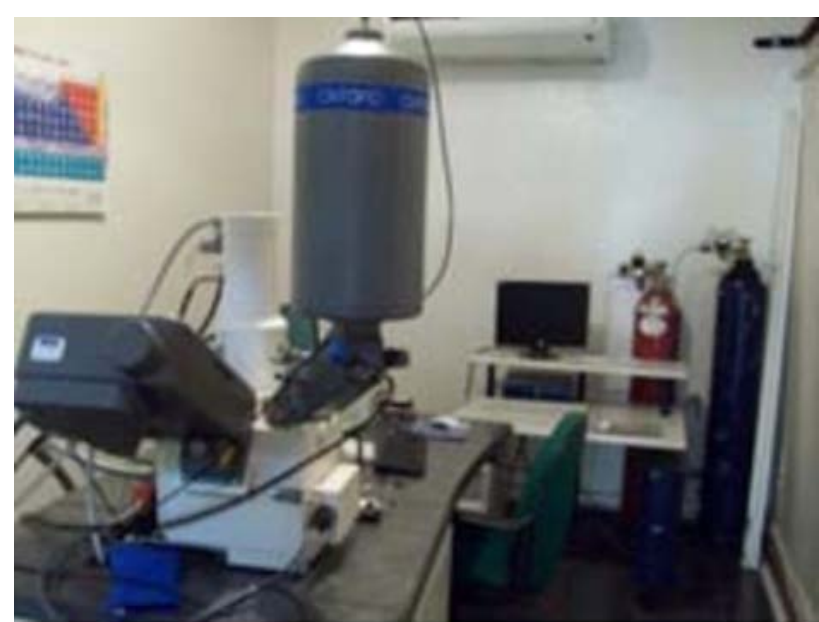

Figure 3. SEM image, retro mode electrons projected. 


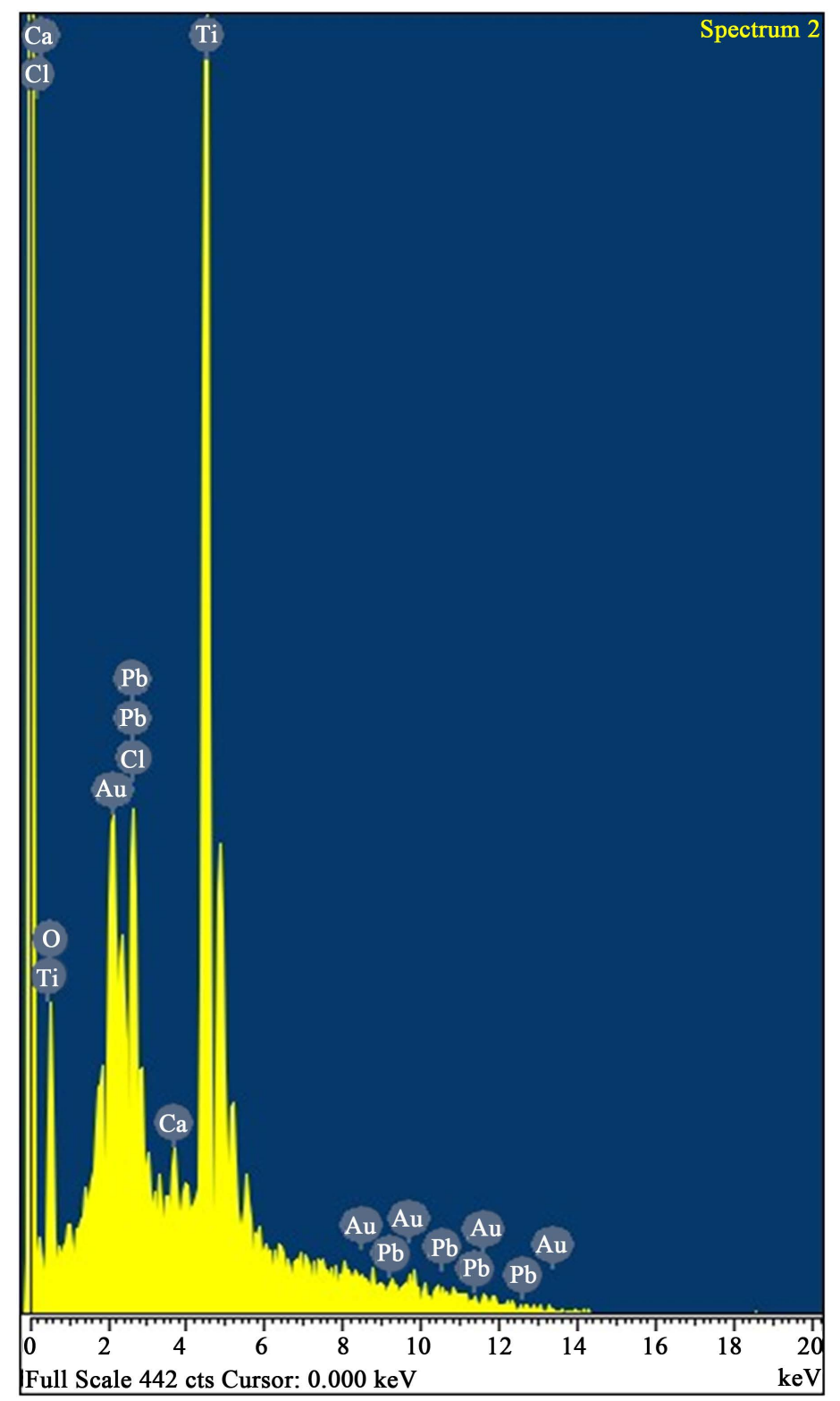

Figure 4. SEM image, retro mode electrons projected.

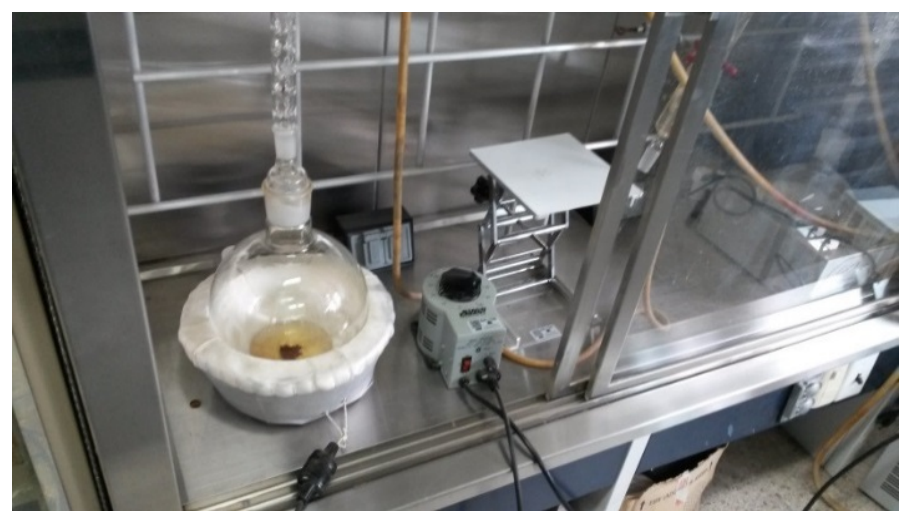

Figure 5. Reactor where leaching takes place. 
Free electronic components are grouped by categories, processors, resistors, diodes, RAM memory, transistors and capacitors, which allows us to define the chemical composition of the metal fraction and the relations between these species present in electronic components.

SEM applied to the different components of the electronic cards, were permitted to set the contents of the metals of interest of research, and which contains higher amount of gold is the processor pins.

Pin processors, were reduced in size by two stages before cutting the electronic material; The cutting was carried out with industrial scissors of steel, which allowed the material to a size below half an inch; and spraying was carried out using a mechanical mill.

They are suited for the chemical leaches of electronic material, the methodology proposed by Mahmoud to leaches and Sulphur metals of the Platinum Group respectively [6].

Mahmoud methodology proposes leaches metals of the platinum group with sulfuric acid and sodium chloride, controlling the temperature above 90 degrees Celsius.

The leaches are developed in the laboratory of chemistry 3, the FCQI, using the equipment shown in Figure 2, over grills that allowed the temperature and the agitation produced by magnets, all on a hood that evacuates gases.

After leaching of materials of the processor's pins, different fractions and liquors of the developed tests, samples shall be taken to be subjected to analysis of atomic absorption in laboratories (pending laboratory where testing).

For the material product of the cards mother will dissolve with aqua regía a weight determined in the laboratory (same PIN processing equipment). The readings were made for metals copper, iron, silver, gold and the platinum group. In each leaching level solute samples shall be taken and collected the liqueur at the end of the procedure, in order to recognize the leached metal fraction. Spirits of the leaches, was measuring at 400 and 1000 $\mathrm{ml}$, and will analyze the content of copper, iron, silver, gold and the platinum group.

\section{Results and Discussion}

The characterization of the electronics for the analytical technique SEM, defined compositionally homogeneous phases and textures ductile various metals which constitute the electronic Board regarding research, the Association of the metal with the type of electronic component and various metallic alloys in the TCI as $\mathrm{Ni} / \mathrm{Zn}$ and $\mathrm{Cu} / \mathrm{Ni}$, also allowed to determine the Association of the gold alloy with copper-level iron and nickel, and coverage that suffer the metals in the TCI with polymer phases.

Table 1 shows the results of the leaches made with 80 grams of sample and extrapolated to gr/tons of material. Gold is contained mostly in the material associated with the copper, this type of material represents $30 \%$ of the total content in the "rest of the card", while the processor contains $36 \%$ of the gold contained in the rest of the card, a situation due to the volume of material that this represents total respect, on the other hand the content of non-metallic is above $55 \%$ on average.

In Figure 6, the spectrum of chemical analysis of the surface of the PCB, after leaching, it was determined that alloy has a $93.59 \%$ gold and $6.41 \%$ niobium. This implies that niobium is in a gold matrix. Because the solubility of gold in acid solution enables recovery of the gold solution and niobium.

In the case of ICT, the existence nickel alloy gold and niobium present in the pins, it is necessary to dissolve all the nickel solution for gold.

In Figure 7, the spectrum of the chemical analysis of the surface of the TCI, after the acid leaching and basic determinant the alloy has a $90.34 \%$ nickel, $9.21 \%$ gold and $0.44 \%$ shown niobium.

Table 1. Results calculations of the leaching using the estequiometrías reactions.

\begin{tabular}{|c|c|c|c|c|}
\hline \multirow{2}{*}{ Fraction } & \multicolumn{4}{|c|}{ gr/ton. material } \\
\hline & $\mathrm{Ag}$ & $\mathrm{Au}$ & $\mathrm{Pt}$ & $\mathrm{Cu}$ \\
\hline Metal pin processor & 54.01 & 251.90 & 0.34 & 0.0 \\
\hline Metal in TCI & 129.10 & 73.78 & 0.67 & 155.80 \\
\hline
\end{tabular}




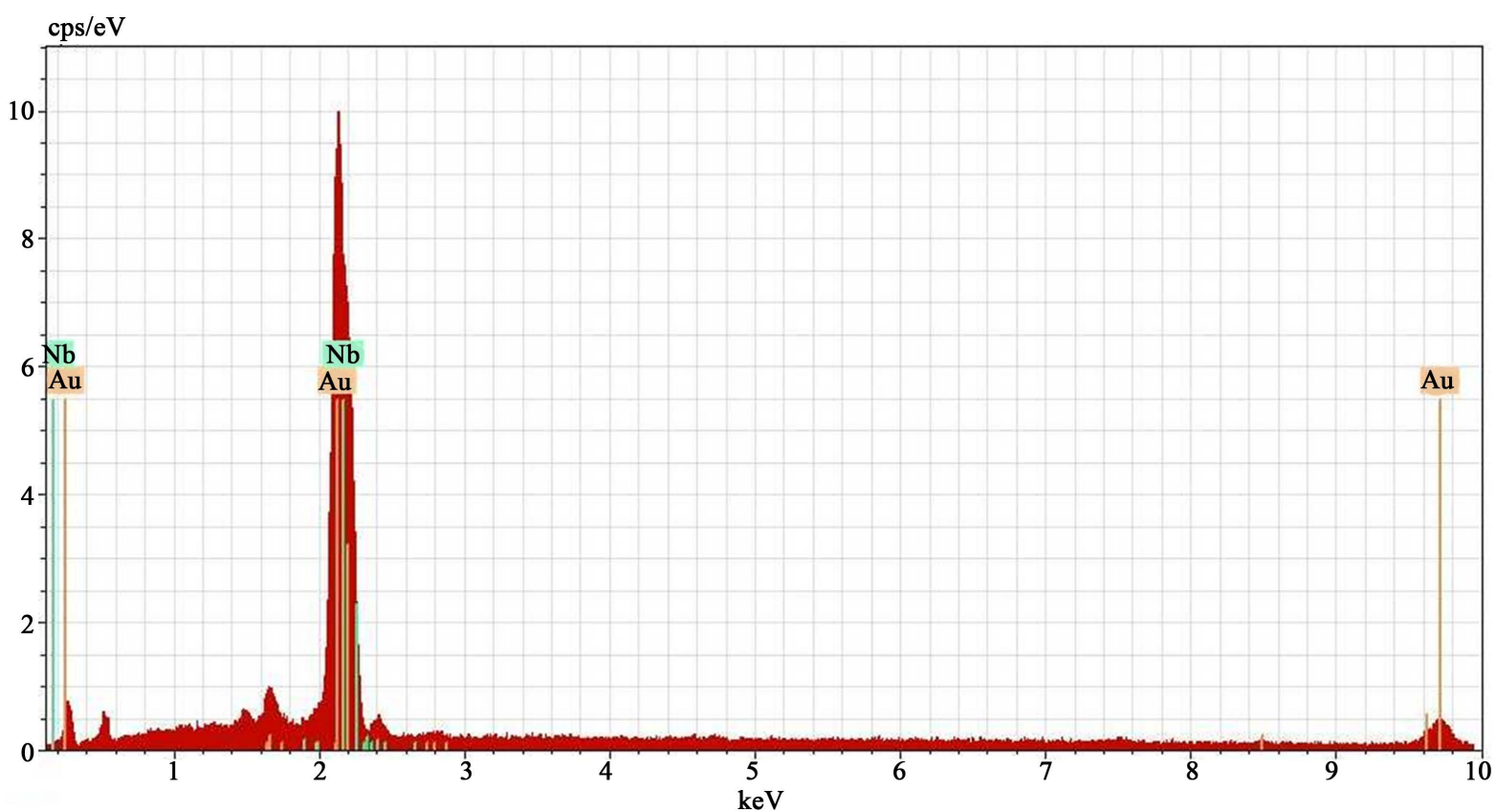

Figure 6. Spectrum chemical analysis of the surface of the alloy coated TCI gold-niobium.

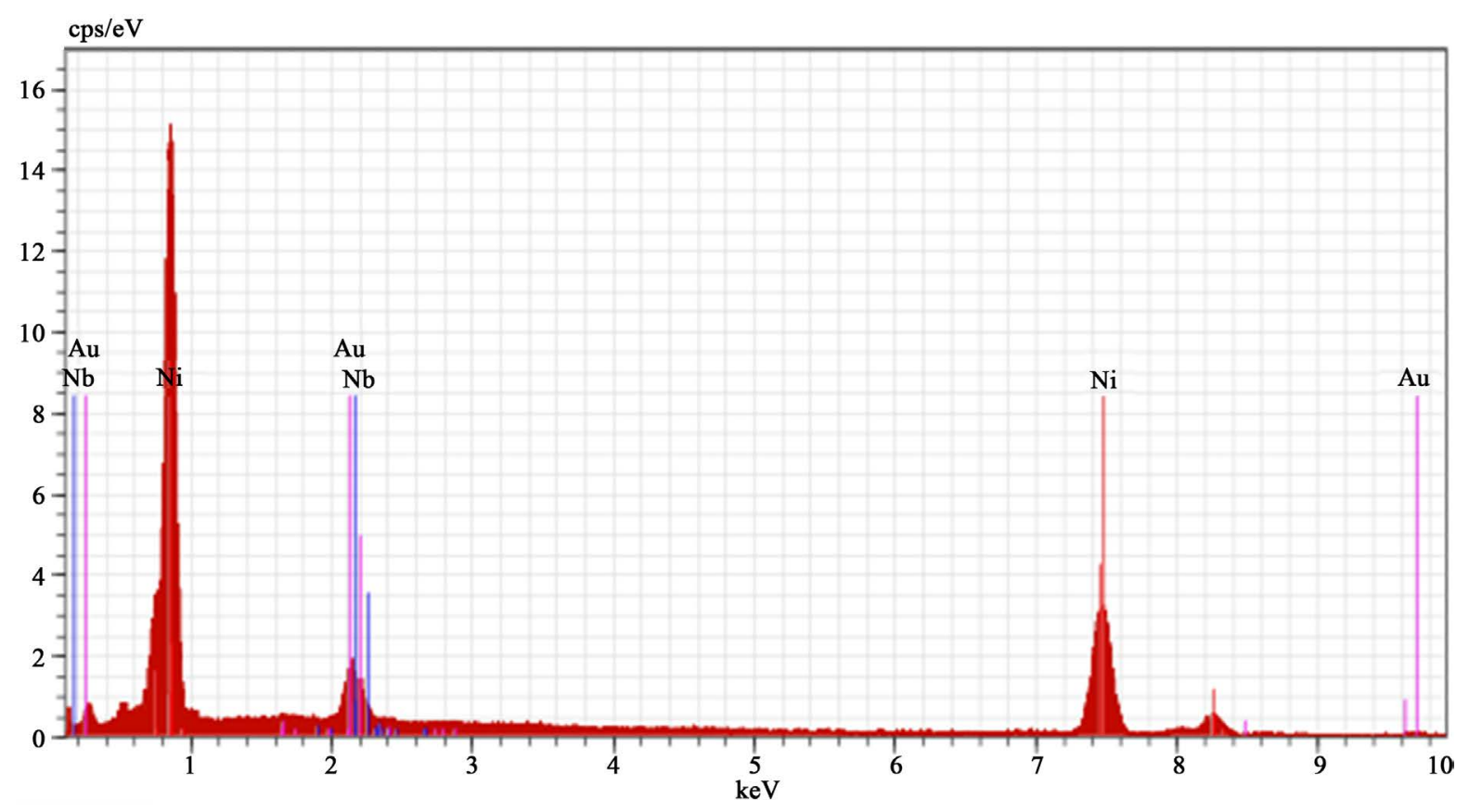

Figure 7. Image surface chemical analysis TCI electron microscopy at 1000×.

\section{Conclusions}

In leaching $\mathrm{HNO}_{3}$ there were obtained three products in the leach liquor: the first one containing a metals diluted sample, the second one silver precipitated in the form of $\mathrm{AgCl}$, and finally, solid waste liquor containing gold, which did not react with $\mathrm{HNO}_{3}$.

Samples of liquor generated in each experiment were designed for analysis Chemical Absorption Spectrometry Atomic (AA), in order to determine the concentration of gold, silver and copper are metals with the highest proportion in alloy. 
According to the factorial method, for degree of statistical confidence of $95 \%$, the only variable that influences the silver extraction percentage for sample 1 was the temperature, presenting a negative influence. That is, the percentage of silver extraction decreases with increasing temperature from $25^{\circ} \mathrm{C}$ to $60^{\circ} \mathrm{C}$. For the sample 2 , the descending order of influence experimental positive response was given by leaching time and temperature.

The optimization of results experimental by the statistical method step up the conditions determined for maximum extraction of silver (100\%) and copper (100\%) using $0.5 \mathrm{~g}$ sample. Conditions optimal were: $32 \mathrm{~mL}$ of $\mathrm{HNO}_{3}, 1.5$ hours and a temperature of $42^{\circ} \mathrm{C}$ for sample 1 and $45 \mathrm{~mL}$ of $\mathrm{HNO}_{3}, 2.25 \mathrm{~h}$ and $43^{\circ} \mathrm{C}$ for sample 2 . These results showed that in both samples it requires an average temperature of $42^{\circ} \mathrm{C}$ for maximum extraction silver and copper.

\section{References}

[1] McAllister, B. (1992) United Nations Conference on Environment and Development: An Opportunity to Forge a New Unity in the Work of the World Bank among Human Rights, the Environment, and Sustainable Development. HastingsInt'lComp.L.Rev., 16, 689.

[2] Unidas, O.D.L.N. (1992) Conferencia de las Naciones Unidas Sobre el Medio Ambiente y el Desarrollo. Conferencia de las Naciones Unidas Río de Janeiro.

[3] Avila, M.E.G. (2012) Guía municipal de gestión integral de residuos de aparatos eléctricos y electrónicos” para el noreste de México. Residuos.

[4] Boeni, H., Silva, U. and Ott, D. (2009) Reciclaje de residuos electrónicos en América Latina. Panorama general, desafíos y potencial. Gestión de residuos electrónicos en América Latina, 51.

[5] Cortes, M.A., et al. (2013) Spectroscopic Characterization Technical High Resolution of Gold from a Memory Card RAM. In: Advanced Materials Research. Trans Tech Publ.

[6] Mahmoud, M. (2003) Leaching Platinum-Group Metals in a Sulfuric Acid/Chloride Solution. JOM, 55, 37-40. http://dx.doi.org/10.1007/s11837-003-0086-y 